\title{
Review
}

Cerebrovascular Diseases
Cerebrovasc Dis 2017;43:68-75

DOI: $10.1159 / 000453282$
Received: September 2, 2016

Accepted: November 7, 2016

Published online: November 30, 2016

\section{Recent Update on Carotid Endarterectomy versus Carotid Artery Stenting}

\author{
Raywat Noiphithak $^{\mathrm{a}}$ Anusak Liengudom ${ }^{\mathrm{b}}$ \\ ${ }^{a}$ Division of Neurosurgery, Department of Surgery, Thammasat University Hospital, Faculty of Medicine, Thammasat \\ University, Pathumthani, and ${ }^{\mathrm{b}}$ Department of Neurosurgery, Prasat Neurological Institute, Bangkok, Thailand
}

\section{Key Words}

Carotid artery stenosis - Carotid endarterectomy . Carotid artery stenting $\cdot$ Carotid artery interventions . Risk stratification

\begin{abstract}
Carotid artery stenosis (CS) is a major cause of ischemic stroke. Treatment of CS consists of best medical treatment and carotid revascularization (CR), including carotid endarterectomy (CEA) and carotid artery stenting (CAS). Both CR techniques have their own procedural risks. Therefore, selection of the appropriate treatment for patients with CS is relatively complicated. Many studies and guidelines have reported the efficacy of each treatment for both symptomatic and asymptomatic patients. However, the results are still controversial, especially concerning the efficacy and safety of CEA and CAS. In this paper, we review and discuss the current evidence and compare results from studies of CEA and CAS, including major randomized trials, meta-analyses and ongoing trials. Moreover, based on the current data, we propose a new comprehensive decision-making for the management of $\mathrm{CS}$.

(c) 2016 S. Karger AG, Basel
\end{abstract}

\section{Introduction}

Carotid artery stenosis (CS) accounts for up to $20-25 \%$ of all ischemic strokes [1]. Treatment of this disease consists of the best medical treatment (BMT) and carotid revascularization (CR), including carotid endarterectomy (CEA) and carotid artery stenting (CAS).

CEA and CAS are recommended for symptomatic patients who have more than $50 \%$ stenosis or asymptomatic patients who have more than $70 \%$ stenosis [2]. Although CEA is the standard treatment and has been shown to benefit patients who have had indications of CS for a long time [3-5], it has some limitations because of patients' comorbidities, unfavorable neck anatomy and surgical complications. CAS, therefore, has been developed to increase safety and provide a minimally invasive procedure. However, there are also concerns associated with CAS because of its periprocedural complications, especially stroke.

Therefore, whether CS is optimally managed with CEA or CAS remains controversial. This review intends to draw a comparison between the results of CEA and CAS and describe a process for reasonable decision-making in choosing the appropriate treatment.

\section{KARGER}

(c) 2016 S. Karger AG, Basel

E-Mail karger@karger.com

www.karger.com/ced
Raywat Noiphithak

Division of Neurosurgery

Department of Surgery, Thammasat University Hospital

95 Klongneung, Klongluang, Pathumthani 12120 (Thailand)

E-Mail raywat_n@yahoo.co.th 


\section{Evidence Data of CEA vs. CAS}

In recent years, there are numerous studies on CAS in comparison with CEA. Although most of the early studies on CAS yielded disappointing results, it has been argued that those trials had some pitfalls. Moreover, there were differences in the experience among interventionists in those trials, and various different stenting systems had been used.

\section{Randomized Trials of CEA vs. CAS}

The Carotid and Vertebral Artery Transluminal Angioplasty Study (CAVATAS) [6] was an early multicenter trial that showed no significant difference in the rates of disabling stroke or death between carotid balloon angioplasty and CEA in patients with CS $(\mathrm{p}=0.8)$. However, this study was underpowered to measure the equality because the inclusion and exclusion criteria were not strict, and no embolic protection devices (EPD) were available at that time. Moreover, only $26 \%$ of patients in the endovascular treatment arm were provided with stents, which resulted in a high rate of re-stenosis and stroke at the 8-year follow-up [7].

In the Stenting and Angioplasty with Protection in $\mathrm{Pa}$ tients at High Risk for Endarterectomy [8] trial conducted in North America, 334 high-risk patients were randomly treated with either CAS (with EPD) or CEA. This study favored CAS over CEA in a non-inferiority analysis $(\mathrm{p}=0.004)$ whereas long-term results at 3 years were not different between the 2 treatment groups [9]. However, this study has been criticized for several reasons. First, it was terminated prematurely because of competing with nonrandomized stent registries, which may have decreased the power of the study. Second, most patients in this trial were asymptomatic. Finally, asymptomatic myocardial enzyme leakage was counted as myocardial infarction (MI).

Later, there were 3 large randomized trials conducted in Europe that reported similar results favoring CEA over CAS. First, the Stent-Protected Angioplasty versus Carotid Endarterectomy (SPACE) [10] trial, a multicenter international study, which was terminated early because of slow enrollment and lack of funding, failed to prove the non-inferiority of CAS ( $\mathrm{p}=0.09$ ). Second, the Endarterectomy versus Angioplasty in Patients with Symptomatic Severe Carotid Stenosis (EVA-3S) [11] study was a French multicenter, randomized study that included 527 patients. It was terminated prematurely because of a significantly higher rate of death or stroke in CAS than CEA $(p=0.01)$ at 30 days. The cumulative probabilities of event were also significantly higher in CAS $(p=0.04)$ at a 5-year follow-up, but they were not significant at a 10 -year follow-up $(\mathrm{p}=0.07)$ [12]. Lastly, the International Carotid Stenting Study (ICSS or CAVATAS-II) [13] enrolled 1,713 patients with $>50 \%$ symptomatic CS from 50 centers worldwide. The 120 day rate of stroke, MI or death was significantly higher in CAS ( $p=0.006)$. Furthermore, new ischemic lesions were found more frequently in CAS than in CEA [14]. Although the 5-year results of this study showed similarity in the incidence of fatal or disabling stroke between CAS and CEA, the cumulative risk of any stroke in CAS was significantly higher than in CEA $(\mathrm{p}<0.001)$ [15]. However, the inferior efficacy of CAS compared with CEA remains inconclusive from the results of SPACE, EVA-3S and ICSS because there were some pitfalls in the study designs. First, EPDs were not required in any of these trials. Second, there was variation in the type of stent used in the studies (SPACE and EVA-3S). Third, dual antiplatelet therapy for CAS, which is beneficial to prevent thrombi on the stent, was not mandatory (EVA-3S, ICSS). Finally, the results from these trials implied that periprocedural complication rates relied on the experience of the interventionists. Calvet et al. [16] concluded that carotid stenting should only be performed at centers where interventionists can perform $>6$ CAS procedures every year.

The Carotid Revascularization Endarterectomy versus Stenting Trial (CREST) [17], a large, randomized, multicenter trial from North America, was published several months after ICSS. This trial included 2,502 patients who were both symptomatic and asymptomatic assigned to CAS or CEA. CAS was performed with only one stent type and EPD was mandatory whenever technically feasible. In addition, pre- and post-procedural antiplatelet therapies were required. The interventionists in this trial were trained and evaluated strictly in the leadin phase. There was no difference in the rates of primary end point between CAS and CEA $(p=0.51)$. However, periprocedural stroke rate was higher in the CAS than in the CEA $(\mathrm{p}=0.01)$, whereas the incidence of periprocedural MI was higher in the CEA $(p=0.03)$. In the subgroup analysis from CREST, symptomatic patients [18], women [19] and age $>65$ years [20] were factors associated with a higher rate of stroke and death rates in the CAS .

Although CREST is the largest study to date and showed an acceptable outcome for CAS compared with CEA, it has been criticized for several reasons. First, CREST originally enrolled only symptomatic patients, 
Table 1. Results from large randomized trials of CEA vs. CAS

\begin{tabular}{|c|c|c|c|c|c|c|c|c|}
\hline Name & Number & EPD use, $\%$ & \multicolumn{2}{|c|}{ Periprocedural* D/S } & $\mathrm{p}$ value & \multicolumn{2}{|c|}{ Periprocedural D/S/MI } & $\mathrm{p}$ value \\
\hline SAPPHIRE [8], 2004 & 334 & 95.6 & 8.4 & 5.5 & 0.36 & 20.2 & 12.2 & 0.004 \\
\hline SPACE [10], 2006 & 1,200 & 27 & 6.3 & 6.8 & 0.09 & NA & NA & NA \\
\hline EVA-3S [11], 2008 & 527 & 91.9 & 3.9 & 9.6 & 0.01 & NA & NA & NA \\
\hline
\end{tabular}

$\mathrm{D} / \mathrm{S}=$ Death or stroke; $\mathrm{D} / \mathrm{S} / \mathrm{MI}=$ death, stroke or $\mathrm{MI} ; \mathrm{NA}=$ not available.

* Periprocedural period was defined in most studies as the 30 days after the intervention.

but asymptomatic patients were included later because of slow enrollment, which is likely to have diluted the power on the divergence of the primary outcome between CAS and CEA in symptomatic patients. Second, it was debatable whether MI should have been included as the primary end point because it is not a treatment goal of CR. Moreover, CREST showed that MI had fewer adverse effects than stroke on the quality of life of patients at 1 year $[17,21]$. Definition of MI in CREST was unusual and possibly overestimated. Despite fewer periprocedural MI in CAS, there were $>2.5$-fold more MI after CAS than CEA at 4 years. Worth noting, the 4 -year MI rate was not a component of the primary end point. In addition, a greater proportion of late deaths were observed in CAS patients who had suffered a periprocedural MI [22]. Third, it is questionable to apply the results from CREST to routine practice because the interventionists in CREST were trained rigorously in the lead-in phase. Finally, the protocol specified the use of only RX Acculink stents and RX Accunet EPDs, which are big, open-cell design stents and large-pored filters, respectively, that can cause distal embolization. Summarized data from the studies described above are illustrated in table 1.

In the same year of CREST publication, the American Heart Association (AHA) and 13 other related societies [2] published guidelines stating that CAS is an alternative to CEA for symptomatic patients, although the data obviously reveal that CEA remains safer. Furthermore, these guidelines recommended that prophylactic CAS might be considered in highly selected asymptomatic patients, but they rated the level of evidence for this suggestion as class IIb. The background of these guidelines was mainly based on the results of CREST, which made it substantially different from the other guidelines, espe- cially the guidelines from the Societies of Vascular Surgery [23]. On the contrary, the American Society for Vascular Surgery [24] published an update of their 2008 guidelines 2 months after the publication of AHA guidelines stating that their guidelines were more circumspect with regard to the role of CAS and a more supportive role of CEA. Kakisis et al. [25] reviewed the 2009 European Society for Vascular Surgery guidelines and also found that CEA is preferable to CAS for the majority of symptomatic patients. However, both guidelines of the vascular societies did not recommend CAS for asymptomatic patients.

\section{Meta-Analysis of Randomized Trials}

Recent meta-analyses [26-32], which included the latest large studies, seem to support the superiority of CEA over CAS in the periprocedural period whereas longterm results are inconclusive (table 2). The meta-analysis [29] published in 2011 showed that CAS, when compared with CEA, was associated with an increased risk of periprocedural outcomes of death, MI or stroke except for cranial nerve injury and MI. In addition, CAS was associated with $19 \%$ increase in the risk for the composite of periprocedural death, MI or stroke plus ipsilateral stroke in the intermediate to long-term outcomes. A meta-analysis of Vincent et al. [30] revealed that the higher cumulative incidence of stroke-related events throughout long-term follow-up was possibly caused by an increased risk during the periprocedural period. Interestingly, Zhang et al. [32] systematically reviewed the data comparing CAS with CEA in the treatment of CS and pooled the data to analyze the results in different aspects. This study concluded that CEA is superior to CAS with regard to the stroke or death rate within 30 days, especially from 2006 to 2015, in North America and Europe. 
Table 2. List of meta-analyses of CEA vs. CAS

\begin{tabular}{|c|c|c|c|c|}
\hline Name & $\begin{array}{l}\text { Number of } \\
\text { studies }\end{array}$ & Number & Periprocedural results (within 30 days) & Long-term results \\
\hline Meier et al. [26], 2010 & 11 & 4,796 & Lower risk of D/S for CEA & No difference up to 4 years \\
\hline Liu et al. [27], 2012 & 13 & 7,501 & Significantly higher risk of D/S for CAS & No difference up to 1 year \\
\hline Bonati et al. [28], 2011 & 3 & 3,433 & Higher risk of $\mathrm{D} / \mathrm{S}$ for CAS & Higher 120 -day risk of S/D for CAS \\
\hline Bangalore et al. [30], 2011 & 13 & 7,477 & $\begin{array}{l}\text { CAS was associated with a significantly } \\
\text { higher risk of D/S/MI and D/S }\end{array}$ & $\begin{array}{l}\text { Higher risk of both } \mathrm{D} / \mathrm{S} / \mathrm{MI} \text { and } \mathrm{D} / \mathrm{S} \\
\text { for CAS ( }>40 \text { months) }\end{array}$ \\
\hline Vincent et al. [31], 2015 & 8 & 7,091 & Significant higher risk of D/S for CAS & $\begin{array}{l}\text { Risk of any long-term stroke was } \\
\text { significantly higher with CAS } \\
(2-10 \text { years })\end{array}$ \\
\hline
\end{tabular}

The superiority was also observed at 4- and 10-year follow-up. On the contrary, the efficacy of CEA was inferior to that of CAS for the stroke or death rate at 1-year follow-up.

\section{Ongoing Randomized Trials of Asymptomatic Carotid} Stenosis

Regarding the lack of evidence in asymptomatic patients and the fact that medical therapy has been improved, large ongoing trials are being conducted to compare the efficacy between CR and BMT. Carotid Stenting vs. Surgery of Severe Carotid Artery Disease and Stroke Prevention in Asymptomatic Patients (ACTI) [33] was a multicenter, randomized trial of CAS vs. CEA for asymptomatic severe CS. This study was terminated because of slow recruitment. The results from 1,453 patients in this study showed a higher rate of stroke in CAS compared with CEA but it did not reach statistical significance.

Asymptomatic Carotid Surgery Trial-2 [34] is an ongoing trial planning to enroll 5,000 patients with asymptomatic severe CS and assign them randomly to CAS or CEA. The study has enrolled over 1,200 patients to date and has revealed a $1 \%$ rate of 30 -day stroke, MI or death.

SPACE-2 [35], started in 2008, first began randomization with a 3 -arm trial - BMT alone vs. CAS plus BMT vs. CEA plus BMT. Because of slow enrollment, the study design was revised into 2 parallel 2-arm trials in 2013: CEA plus BMT vs. BMT alone (SPACE-2A) and CAS plus BMT vs. BMT alone (SPACE-2B). However, the revision of the design did not affect the enrollment and the trial was halted after recruiting 513 patients. The 30 -day rate of stroke or death was $2.54 \%$ in the CAS group and $1.97 \%$ in the CEA group whereas no patient in the BMT group had stroke or death.

Currently, CREST-2 is a large, multicenter, randomized trial, assigning patients to 2 parallel trials, similar to the SPACE-2. The primary end point is a 30-day rate of stroke or death and ipsilateral stroke at a 4-year followup. The study started to recruit patients in 2014 with a goal of 2,418 patients. It is notable that both SPACE-2 and CREST-2 are not directly comparing CAS with CEA.

Although the previous data showed the superiority of CEA over CAS in symptomatic patients and the results of asymptomatic patients are uncertain, it is remarkable that both CEA and CAS are associated with a risk of procedural complications. In addition, the advanced technology of CAS has been further developed and the CAS operators have gained more experience in the past few years. A consensus from Italy [36] recommended specific training to achieve basic competence and technical skill as the primary operator for performing CAS in order to improve the outcomes. Therefore, the debate between CEA 
Fig. 1. Decision-making diagram of 3 steps for the management of CS. Step I - symptomatic status. Step II - choice of treatment based on severity of stenosis in symptomatic patients and high-risk features in asymptomatic patients. Step III - choice of revascularization based on procedural risk. It is important to additionally consider the surgeon's experience and other risk factors, especially in asymptomatic patients for selecting the treatment options.

Table 4. High-risk features of patients with asymptomatic carotid stenosis

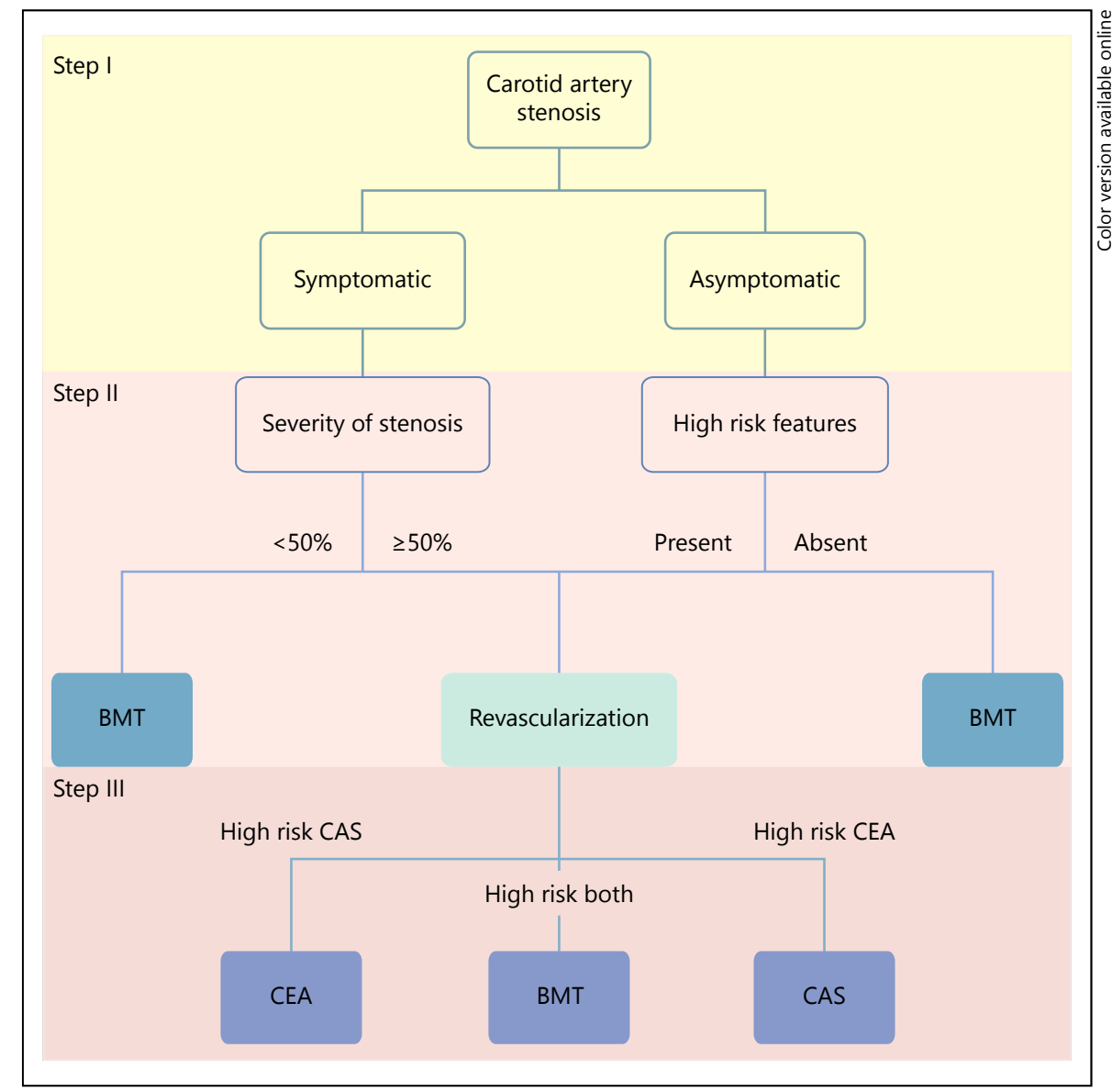

Progression of stenosis

History of contralateral transient ischemic attack or stroke

Unfavorable plaque characteristic on ultrasound (irregularity, ulcerations, echolucency, gray-scale values and plaque area)

Intraplaque hemorrhage on MRI

Microemboli detected by transcranial Doppler ultrasound (TCD)

Silent infarcts on CT

Reduced cerebrovascular reserve patients, and should be based on patient status, plaque characteristics and procedural risk, rather than on the argument between CEA and CAS. Although the data show CEA to be associated with fewer stroke events, there have been advancements in technology and training for CAS, resulting in comparable outcomes between the 2 procedures. Moreover, BMT, including antiplatelet drugs, antihypertensive agents and statins, has also been developed not only to stabilize atherosclerotic lesions but also to break down the plaque. Ongoing trials are investigating the efficacy between new BMT and CR in asymptomatic patients.

\section{Disclosure Statement}

The authors did not receive any specific grant from funding agencies in the public, commercial or not-for-specific sectors. 


\section{References}

1 Petty GW, Brown RD Jr, Whisnant JP, Sicks JD, O'Fallon WM, Wiebers DO: Ischemic stroke subtypes: a population-based study of incidence and risk factors. Stroke 1999;30: 2513-2516.

2 Brott TG, Halperin JL, Abbara S, Bacharach JM, Barr JD, Bush RL, et al: 2011 ASA/ACCF/ AHA/AANN/AANS/ACR/ASNR/CNS/ SAIP/SCAI/SIR/SNIS/SVM/SVS guideline on the management of patients with extracranial carotid and vertebral artery disease: executive summary: a report of the American College of Cardiology Foundation/American Heart Association Task Force on Practice Guidelines, and the American Stroke Association, American Association of Neuroscience Nurses, American Association of Neurological Surgeons, American College of Radiology, American Society of Neuroradiology, Congress of Neurological Surgeons, Society of Atherosclerosis Imaging and Prevention, Society for Cardiovascular Angiography and Interventions, Society of Interventional Radiology, Society of NeuroInterventional Surgery, Society for Vascular Medicine, and Society for Vascular Surgery. Developed in collaboration with the American Academy of Neurology and Society of Cardiovascular Computed Tomography. Catheter Cardiovasc Interv 2013; 81:E76-E123.

3 Ferguson GG, Eliasziw M, Barr HW, Clagett GP, Barnes RW, Wallace MC, et al: The North American Symptomatic Carotid Endarterectomy Trial: surgical results in 1415 patients. Stroke 1999;30:1751-1758.

4 European Carotid Surgery Trialists Collaborative Group: Randomised trial of endarterectomy for recently symptomatic carotid stenosis: final results of the MRC European Carotid Surgery Trial (ECST). Lancet 1998;351: 1379-1387.

5 Walker MD, Marler JR, Goldstein M, et al: Endarterectomy for asymptomatic carotid artery stenosis. JAMA 1995;273:1421-1428.

6 CAVATAS Investigators: Endovascular versus surgical treatment in patients with carotid stenosis in the Carotid and Vertebral Artery Transluminal AngioplastyStudy(CAVATAS): a randomised trial. Lancet 2001;357:1729_ 1737.

7 Ederle J, Bonati LH, Dobson J, Featherstone RL, Gaines PA, Beard JD, et al: Endovascular treatment with angioplasty or stenting versus endarterectomy in patients with carotid artery stenosis in the Carotid And Vertebral Artery Transluminal Angioplasty Study (CAVATAS): long-term follow-up of a randomised trial. Lancet Neurol 2009;8:898-907.

8 Yadav JS, Wholey MH, Kuntz RE, Fayad P, Katzen BT, Mishkel GJ, et al: Protected carotid-artery stenting versus endarterectomy in high-risk patients. N Engl J Med 2004;351: 1493-1501.

9 Gurm HS, Yadav JS, Fayad P, Katzen BT, Mishkel GJ, Bajwa TK, et al: Long-term re- sults of carotid stenting versus endarterectomy in high-risk patients. N Engl J Med 2008; 358:1572-1579.

10 SPACE Collaborative Group, Ringleb PA, Allenberg J, Brückmann H, Eckstein HH, Fraedrich G, et al: 30 day results from the SPACE trial of stent-protected angioplasty versus carotid endarterectomy in symptomatic patients: a randomised non-inferiority trial. Lancet 2006;368:1239-1247.

11 Mas JL, Trinquart L, Leys D, Albucher JF, Rousseau H, Viguier A, et al: Endarterectomy versus angioplasty in patients with symptomatic severe carotid stenosis (EVA-3S) trial: results up to 4 years from a randomised, multicentre trial. Lancet Neurol 2008;7:885-892.

12 Mas JL, Arquizan C, Calvet D, Viguier A, Albucher JF, Piquet P, et al: Long-term followup study of endarterectomy versus angioplasty in patients with symptomatic severe carotid stenosis trial. Stroke 2014;45:2750-2756.

13 International Carotid Stenting Study Investigators, Ederle J, Dobson J, Featherstone RL, Bonati LH, van der Worp HB, et al: Carotid artery stenting compared with endarterectomy in patients with symptomatic carotid stenosis (International Carotid Stenting Study): an interim analysis of a randomised controlled trial. Lancet 2010;375:985-997.

14 Bonati LH, Jongen LM, Haller S, Flach HZ, Dobson J, Nederkoorn PJ, et al: New ischaemic brain lesions on MRI after stenting or endarterectomy for symptomatic carotid stenosis: a substudy of the International Carotid Stenting Study (ICSS). Lancet Neurol 2010;9:353-362.

15 Bonati LH, Dobson J, Featherstone RL, Ederle J, van der Worp HB, de Borst GJ, et al: Long-term outcomes after stenting versus endarterectomy for treatment of symptomatic carotid stenosis: the International Carotid Stenting Study (ICSS) randomised trial. Lancet 2015;385:529-538.

16 Calvet D, Mas JL, Algra A, Becquemin JP, Bonati LH, Dobson J, et al: Carotid stenting: is there an operator effect? A pooled analysis from the carotid stenting trialists' collaboration. Stroke 2014;45:527-532.

17 Brott TG, Hobson RW 2nd, Howard G, Roubin GS, Clark WM, Brooks W, et al: Stenting versus endarterectomy for treatment of carotid-artery stenosis. N Engl J Med 2010;363: 11-23.

18 Silver FL, Mackey A, Clark WM, Brooks W, Timaran $\mathrm{CH}$, Chiu D, et al: Safety of stenting and endarterectomy by symptomatic status in the Carotid Revascularization Endarterectomy versus Stenting Trial (CREST). Stroke 2011;42:675-680.

19 Howard VJ, Lutsep HL, Mackey A, Demaerschalk BM, Sam AD 2nd, Gonzales NR, et al: Influence of sex on outcomes of stenting versus endarterectomy: a subgroup analysis of the Carotid Revascularization Endarterectomy versus Stenting Trial (CREST). Lancet Neurol 2011;10:530-537.
20 Voeks JH, Howard G, Roubin GS, Malas MB, Cohen DJ, Sternbergh WC 3rd, et al: Age and outcomes after carotid stenting and endarterectomy: the carotid revascularization endarterectomy versus stenting trial. Stroke 2011; 42:3484-3490.

21 Cohen DJ, Stolker JM, Wang K, Magnuson EA, Clark WM, Demaerschalk BM, et al: Health-related quality of life after carotid stenting versus carotid endarterectomy: results from CREST (Carotid Revascularization Endarterectomy versus Stenting Trial). J Am Coll Cardiol 2011;58:1557-1565.

22 Blackshear JL, Cutlip DE, Roubin GS, Hill MD, Leimgruber PP, Begg RJ, et al: Myocardial infarction after carotid stenting and endarterectomy: results from the carotid revascularization endarterectomy versus stenting trial. Circulation 2011;123:2571-2578.

23 Paraskevas KI, Mikhailidis DP, Veith FJ: Comparison of the five 2011 guidelines for the treatment of carotid stenosis. J Vasc Surg 2012;55:1504-1508.

24 Ricotta JJ, Aburahma A, Ascher E, Eskandari M, Faries P, Lal BK, et al: Updated Society for Vascular Surgery guidelines for management of extracranial carotid disease. J Vasc Surg 2011;54:e1-e31.

25 Kakisis JD, Avgerinos ED, Antonopoulos CN, Giannakopoulos TG, Moulakakis K, Liapis CD: The European Society for Vascular Surgery guidelines for carotid intervention: an updated independent assessment and literature review. Eur J Vasc Endovasc Surg 2012; 44:238-243.

26 Meier P, Knapp G, Tamhane U, Chaturvedi S, Gurm HS: Short term and intermediate term comparison of endarterectomy versus stenting for carotid artery stenosis: systematic review and meta-analysis of randomised controlled clinical trials. BMJ 2010;340:c467.

27 Liu ZJ, Fu WG, Guo ZY, Shen LG, Shi ZY, $\mathrm{Li} \mathrm{JH}$ : Updated systematic review and meta-analysis of randomized clinical trials comparing carotid artery stenting and carotid endarterectomy in the treatment of carotid stenosis. Ann Vasc Surg 2012;26: 576-590.

28 Bonati LH, Fraedrich G; Carotid Stenting Trialists' Collaboration: Age modifies the relative risk of stenting versus endarterectomy for symptomatic carotid stenosis - a pooled analysis of EVA-3S, SPACE and ICSS. Eur J Vasc Endovasc Surg 2011;41:153-158.

29 Bonati LH, Lyrer P, Ederle J, Featherstone R, Brown MM: Percutaneous transluminal balloon angioplasty and stenting for carotid artery stenosis. Cochrane Database Syst Rev 2012;9:CD000515.

30 Bangalore S, Kumar S, Wetterslev J, Bavry AA, Gluud C, Cutlip DE, et al: Carotid artery stenting vs carotid endarterectomy: metaanalysis and diversity-adjusted trial sequential analysis of randomized trials. Arch Neurol 2011;68:172-184. 
31 Vincent S, Eberg M, Eisenberg MJ, Filion KB: Meta-analysis of randomized controlled trials comparing the long-term outcomes of carotid artery stenting versus endarterectomy. Circ Cardiovasc Qual Outcomes 2015;8(6 suppl 3):S99-S108.

32 Zhang L, Zhao Z, Ouyang Y, Bao J, Lu Q, Feng $\mathrm{R}$, et al: Systematic review and meta-analysis of carotid artery stenting versus endarterectomy for carotid stenosis: a chronological and worldwide study. Medicine (Baltimore) 2015; 94:e1060.

33 Rosenfield K, Matsumura JS, Chaturvedi S, Riles T, Ansel GM, Metzger DC, et al: Randomized trial of stent versus surgery for asymptomatic carotid stenosis. N Engl J Med 2016;374:1011-1020.

34 Bulbulia R, Halliday A: ACST-2 - an update. A large, simple randomised trial to compare carotid endarterectomy versus carotid artery stenting to prevent stroke in asymptomatic patients. Gefasschirurgie 2013;18:626-632.
35 Eckstein HH, Reiff T, Ringleb P, Jansen O, Mansmann U, Hacke W, et al: SPACE-2: a missed opportunity to compare carotid endarterectomy, carotid stenting, and best medical treatment in patients with asymptomatic carotid stenoses. Eur J Vasc Endovasc Surg 2016;51:761-765.

36 Cremonesi A, Setacci C, Bignamini A, Bolognese L, Briganti F, Di Sciascio G, et al: Carotid artery stenting: first consensus document of the ICCS-SPREAD Joint Committee. Stroke 2006;37:2400-2409.

37 Lindsay AC, Biasiolli L, Lee JM, Kylintireas I, MacIntosh BJ, Watt $\mathrm{H}$, et al: Plaque features associated with increased cerebral infarction after minor stroke and TIA: a prospective, case-control, 3-T carotid artery MR imaging study. JACC Cardiovasc Imaging 2012;5:388396.

38 Yoshimura S, Yamada K, Kawasaki M, Asano T, Kanematsu M, Takamatsu M, et al: Highintensity signal on time-of-flight magnetic resonance angiography indicates carotid plaques at high risk for cerebral embolism during stenting. Stroke 2011;42:3132-3137.

39 Spence JD, Song H, Cheng G: Appropriate management of asymptomatic carotid stenosis. Stroke Vasc Neurol 2016;1:e000016.

40 Hadar N, Raman G, Moorthy D, O'Donnell TF, Thaler DE, Feldmann E, et al: Asymptomatic carotid artery stenosis treated with medical therapy alone: temporal trends and implications for risk assessment and the design of future studies. Cerebrovasc Dis 2014;38:163173.

41 Bogiatzi C, Cocker MS, Beanlands R, Spence JD: Identifying high-risk asymptomatic carotid stenosis. Expert Opin Med Diagn 2012; 6:139-151.

42 Singh TD, Kramer CL, Mandrekar J, Lanzino G, Rabinstein AA: Asymptomatic carotid stenosis: risk of progression and development of symptoms. Cerebrovasc Dis 2015;40:236243 